\title{
Triagem neonatal em crianças na região do Médio Paraíba - uma análise preliminar
}

\section{Neonatal screening in children in Médio Paraíba region-a preliminary analysis}

\author{
1 Marcela Leone Pereira de Oliveira marcela.oliveirahh@gmail.com \\ 1 Anderson de Souza Mendonça Junior \\ 1 Isabelly Nascimento Souza \\ 1 Julio Cesar Goulart Fonseca \\ 2 Amanda Freire de Almeida \\ 3 Marian Provazi Orioli \\ 4 Bruno Chaboli Gambarato \\ 5 Luciano Rodrigues Costa \\ 6 Claudia Yamada Utagawa
}

\begin{abstract}
Graduanda(o) do curso de Medicina. Centro Universitário de Volta Redonda - UniFOA.
Graduação em Medicina pela Faculdade de Medicina de Campos.

3 Especialização em Especialização em Terapia Intensiva Pediátrica pelo Neovida - Centro Infantil de Terapia Intensiva. Pediatra Intensivista do Neovida - Centro Infantil de Terapia Intensiva.

4 Doutorado em Biotecnologia Industrial pela Escola de Engenharia de Lorena (USP). Professor Doutor do Centro Universitário de Volta Redonda - UniFOA.

5 Especialização em Pós Graduação Em Gestão Hospitalar pela Escola Nacional de Saúde Pública. Professor Assistente de Pediatria do Centro Universitário de Volta Redonda - UniFOA.

6 Doutorado em Educação, Difusão e Gestão em Biociências pela Universidade Federal do Rio de Janeiro.Professor titular do Centro Universitário de Volta Redonda - UniFOA.
\end{abstract}

\section{RESUMO}

O Programa Nacional de Triagem Neonatal (PNTN) consiste no rastreamento de recém-nascidos com o intuito de identificar doenças congênitas de forma precoce, reduzindo morbimortalidade. O objetivo foi analisar a situação do PNTN em Volta Redonda - RJ. Trata-se de estudo transversal com coleta de dados consolidada através da aplicação de formulários de março a dezembro de 2019. A seleção foi feita através de amostra de conveniência com crianças de 0 a 9 anos acompanhadas nos serviços da rede pública de saúde. Foram totalizados 222 formulários. Desses, $18 \%$ tiveram o resultado anotado na caderneta de saúde da criança (CSC), 73\% não foram anotados e $8 \%$ aguardavam resultado. Das crianças que aguardavam o teste, $83 \%$ ultrapassaram o prazo para a entrega do resultado. Dentre as 204 crianças que haviam recebido o resultado do teste, $2 \%$ possuíam alterações, reforçando o PNTN como ação preventiva. Considerando o prazo para entrega do resultado, observou-se que uma parcela expressiva não o recebeu no tempo adequado. Já em relação ao preenchimento da CSC, o resultado se apresentou insuficiente, sendo aquém do almejado. Conclui-se, assim, que melhorias são necessárias para que PNTN alcance plenamente seu potencial.

Palavras-chave:

Triagem neonatal. Diagnóstico precoce. Anormalidades congênitas.

\begin{abstract}
The National Neonatal Screening Program (PNTN) consists of screening newborns to identify congenital diseases early. The objective of this article is to analyze the situation of the PNTN in Volta Redonda - RJ. It's a crosssectional study with consolidated data collection through the application of forms from March to December in 2019. The selection of the sample was made in a simple random way with children aged from 0 to 9 years accompanied at public health services - SUS. There was a total of 222 forms. From this total of 222 forms, $18 \%$ had the results of the screening recorded in the health handbook, $73 \%$ were not recorded, $8 \%$ were waiting for the result. From the children who were waiting for the result, $83 \%$ exceeded the deadline for delivering it. Among the 204 children who had received the test result, $2 \%$ had altered results, reinforcing the importance of the PNTN as a preventive action. Considering the deadline for delivering the result, it was observed that a significant portion did not receive it in the appropriate time. Regarding the completion of the CSC, the result was insufficient, falling short of what was desired. It is concluded, therefore, that improvements are necessary for PNTN to reach its full potential.
\end{abstract}

Keywords:

Neonatal screening. Early diagnosis. Congenital abnormalities.

\section{Como você deve citar?}

OLIVEIRA, Marcela Leone Pereira de et al. Triagem neonatal em crianças na região do Médio Paraíba - uma análise preliminar. Cadernos UniFOA, Volta Redonda, n. 45, p. 167-176, abril 2021. 


\section{INTRODUÇÃO}

A triagem neonatal, proposta pelo médico norte-americano Robert Guthrie, em 1963, baseia-se no rastreamento da população de recém-nascidos, crianças de zero a 28 dias de vida, com o intuito de se identificar doenças e distúrbios de forma precoce (MINISTÉRIO DA SAÚDE, 2016). Essa detecção precoce permite intervenção por meio de tratamento e acompanhamento adequados, reduzindo a morbimortalidade e melhorando a qualidade de vida de modo geral, uma vez que, independentemente da doença, parece ser sempre melhor identificá-las no período pré-sintomático ou sintomático inicial (SOUZA; SCHWARTZ; GIUGLIANI, 2002; MINISTÉRIO DA SAÚDE, 2016).

No Brasil, chamada de "teste do pezinho", a triagem neonatal bioquímica começou em 1976, na cidade de São Paulo, com o diagnóstico da fenilcetonúria e, em 1980, incorporou-se a detecção precoce do Hipotireoidismo Congênito. No entanto, o Programa Nacional de Triagem Neonatal (PNTN) foi instituído pelo Sistema Único de Saúde (SUS) somente em 6 de junho de 2001, com a Portaria GM/MS nº 822 (SOUZA; SCHWARTZ; GIUGLIANI, 2002; RAMALHO; MAGNA; PAIVA-E-SILVA, 2003; MINISTÉRIO DA SAÚDE, 2016). O PNTN foi dividido em fases de implantação, e suas características estão no quadro a seguir:

Quadro 1. Fases de implantação do Programa Nacional de Triagem Neonatal

\begin{tabular}{|c|c|c|c|}
\hline FASE & DOENÇAS & PORTARIA & UNIVERSALIZAÇÃO \\
\hline FASE I & Hipotireoidismo Congênito; Fenilcetonúria & $\begin{array}{l}\text { Portaria GM/MS n. }{ }^{\circ} 22 \text { de } 15 \text { de } \\
\text { janeiro de } 1992\end{array}$ & 2006 \\
\hline FASE II & $\begin{array}{l}\text { Hipotireoidismo Congênito; Fenilcetonúria; } \\
\text { Doenças Falciformes e outras Hemoglobi- } \\
\text { nopatias }\end{array}$ & $\begin{array}{l}\text { Portaria GM/MS nº } 822 \text { de } 6 \text { de } \\
\text { junho de } 2001\end{array}$ & 2013 \\
\hline FASE III & $\begin{array}{l}\text { Hipotireoidismo Congênito; Fenilcetonúria; } \\
\text { Doenças Falciformes e outras Hemoglobi- } \\
\text { nopatias; } \\
\text { Fibrose Cística }\end{array}$ & $\begin{array}{l}\text { Portaria GM/MS no } 822 \text { de } 6 \text { de } \\
\text { junho de } 2001\end{array}$ & 2013 \\
\hline FASE IV & $\begin{array}{l}\text { Hipotireoidismo Congênito; Fenilcetonúria; } \\
\text { Doenças Falciformes e outras Hemoglobi- } \\
\text { nopatias; } \\
\text { Fibrose Cística; } \\
\text { Hiperplasia Adrenal Congênita; Deficiência } \\
\text { da Biotinidase }\end{array}$ & $\begin{array}{l}\text { Portaria PT/GM n² } 2.829 \text {, de } 14 \\
\text { de dezembro de } 2012\end{array}$ & 2014 \\
\hline
\end{tabular}

Fonte: Elaborado pelos autores com base em (MINISTÉRIO DA SAÚDE; DEPARTAMENTO DE ATENÇÃO ESPECIALIZADA, 2005; BRASIL; MINISTÉRIO DA SAÚDE; GABINETE DO MINISTRO, 2012; MINISTÉRIO DA SAÚDE, 2017)

O rastreio é realizado com doenças que deveriam ser alvo prioritário das políticas públicas de saúde (SOUZA; SCHWARTZ; GIUGLIANI, 2002). Os princípios que levam à inclusão de uma doença no PNTN são: não apresentar sintomas precoces; ser facilmente detectado em exames laboratoriais; permitir a realização de testes com altas especificidade e sensibilidade; ser economicamente viável e com um sistema logístico para o acompanhamento dos casos detectados até o diagnóstico final do tratamento (SOUZA; SCHWARTZ; GIUGLIANI, 2002; KHOURY; MCCABE; MCCABE, 2003; LINDEGREN et al., 2004; MINISTÉRIO DA SAÚDE, 2016).

A triagem neonatal apresenta tanto benefícios quanto riscos. Dentre os benefícios, está o diagnóstico precoce de doenças graves e tratáveis ainda antes do quadro sintomático, prevenindo até mesmo o óbito e a possibilidade do aconselhamento genético e reprodução consciente para os portadores de determinadas patologias. Os riscos mais expressivos se dão pelo fato de a primeira fase da triagem buscar o diagnóstico presuntivo e não definitivo, podendo ocorrer, então, resultados falso-negativos e falso-positivos (MINISTÉRIO 
Marcela Leone Pereira de Oliveira / Anderson de Souza Mendonça Junior / Isabelly Nascimento Souza / Julio Cesar Goulart Fonseca / Amanda Freire de Almeida / Marian Provazi Orioli / Bruno Chaboli Gambarato Luciano Rodrigues Costa / Claudia Yamada Utagawa

DA SAÚDE, 2016; LUMERTZ et al., 2019). Os falso-negativos impedem o diagnóstico precoce das doenças triadas, já os falso-positivos podem causar ansiedade aos genitores (LEÃO; AGUIAR, 2008).

Apesar de buscar cobertura de $100 \%$ dos nascidos vivos pelo PNTN, o boletim epidemiológico do Ministério da Saúde mostrou que essa cobertura foi de $85,80 \%$, em 2017 . Além disso, divergindo do esperado, a cobertura do PNTN não possui um crescimento estável, oscilando entre os anos (MINISTÉRIO DA SAÚDE, 2018).

Assim, a triagem neonatal é de extrema importância para o diagnóstico e tratamento precoce de diversas doenças, evitando, dessa maneira, o desenvolvimento de sinais e sintomas, sequelas e até mesmo morte. No entanto, para que ela exerça sua função, além de ser primordial ampliar a cobertura do PNTN, é preciso que o processo da triagem seja rigoroso, seguindo corretamente as etapas preconizadas.

Portanto, o presente trabalho tem por objetivo analisar a situação da triagem neonatal em crianças da região do Médio Paraíba, atendidas pelo Sistema Único de Saúde (SUS) do município de Volta Redonda, a fim de colaborar com o aprimoramento dos programas de saúde nacional, estadual e municipal.

\section{METODOLOGIA}

Trata-se de um estudo observacional transversal, no qual o examinador não realiza intervenções sobre os sujeitos de pesquisa e ocorre um recorte momentâneo de uma população por meio de um espaço amostral. A coleta de dados foi consolidada por meio da aplicação de formulários, sendo feita a seleção por amostra de conveniência com crianças acompanhadas no SUS do município de Volta Redonda, Rio de Janeiro.

Os formulários aplicados foram preenchidos pelo entrevistador de acordo com as respostas fornecidas pelos responsáveis das crianças e dados retirados das cadernetas de saúde. Os critérios de inclusão foram pacientes de 0 a 9 anos ( $<10$ anos), na data da coleta, usuários da rede pública do município de Volta Redonda, com o objetivo de se avaliar a situação do PNTN na última década. A faixa etária da amostra foi escolhida baseada no uso dos dados informados na caderneta de saúde da criança pela mãe e nos gráficos utilizados pela pediatra, como o Índice de Massa Corpórea (IMC), que contempla a faixa de até 10 anos de idade. Não houve critérios de exclusão.

As variáveis avaliadas na pesquisa foram: realização ou não do "teste do pezinho" segundo informações colhidas, se o resultado foi anotado na caderneta de saúde; quais foram as patologias investigadas, caso o teste tenha sido efetuado (hipotireoidismo congênito, fenilcetonúria, doença falciforme/ hemoglobinopatias, fibrose cística, hiperplasia adrenal congênita, deficiência de biotinidase e outros) e seus resultados informados pelo acompanhante ou retirados da caderneta de saúde Criança (CSC).

Os dados coletados foram tabulados e analisados, utilizando-se o software Excel (Office 365, Microsoft, Redmond, WA, EUA). A análise estatística foi realizada no software Microsoft Power BI.

A presente pesquisa foi submetida e aprovada pelo Comitê de Ética em Pesquisa em Seres Humanos (COEPS) da Fundação Oswaldo Aranha - FOA, sob o número do CAAE 01767018.3.0000.5237 e os responsáveis legais pelos pacientes assinaram um Termo de Consentimento Livre e Esclarecido (TCLE). 


\section{RESULTADOS}

Foram aplicados 230 formulários, respondidos pelos responsáveis das crianças. Desse total, oito foram descartados por não preencherem o critério de idade, totalizando 222. Das crianças avaliadas, $50 \%(n=112)$ são do sexo masculino, $47 \%(n=105)$ do sexo feminino e, em $3 \%(n=5)$ dos formulários, não constavam o sexo. Quanto à distribuição em faixas etárias, os dados estão no gráfico a seguir:

Figura 1. Distribuição dos sujeitos de pesquisa por faixa etária em anos

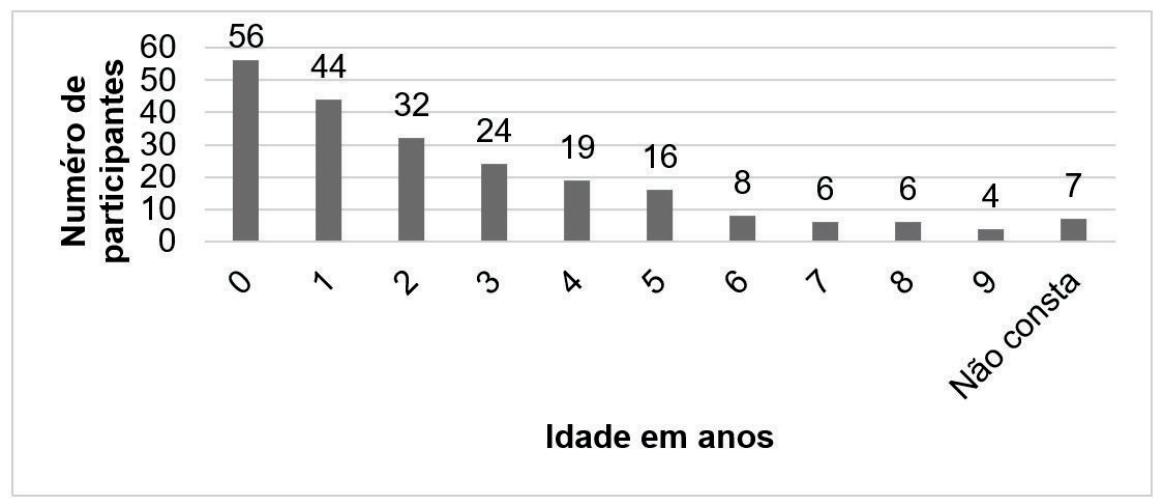

Fonte: Confeccionada pelos autores

Quando questionados sobre a realização ou não do "teste do pezinho", 97,3\% ( $n=216)$ dos acompanhantes relataram que o teste foi realizado e $2,7 \%(n=6)$ não sabiam informar. Dos participantes, $18 \%(n=39)$ tiveram o resultado da triagem bioquímica anotado na caderneta de saúde da criança, $73 \%$ $(n=162)$ dos resultados não foram anotados, $8 \%(n=18)$ estavam aguardando o resultado e $1 \%(n=3)$ não respondeu ao questionamento.

Figura 2. Distribuição dos sujeitos de pesquisa $(n=222)$ de acordo com a situação da caderneta de saúde: 0 resultado foi anotado?

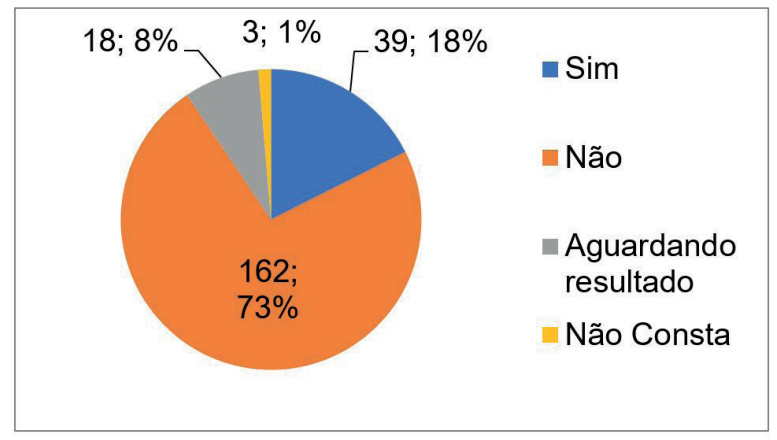

Fonte: Confeccionado pelos autores

As idades dos sujeitos de pesquisa que estavam aguardando o resultado do teste são: dez dias, dezessete dias, vinte e três dias, um mês (2 participantes), dois meses (2 participantes), três meses, cinco meses, seis meses, sete meses, nove meses, onze meses, um ano, dois anos e três anos. Não foi possível calcular a idade exata de dois participantes, pois não constava a data da coleta nos formulários.

Os resultados da triagem dos 204 participantes que já haviam obtido o resultado na data da coleta, discriminado pelas doenças triadas, constam na tabela a seguir: 
Marcela Leone Pereira de Oliveira / Anderson de Souza Mendonça Junior / Isabelly Nascimento Souza / Julio Cesar Goulart Fonseca / Amanda Freire de Almeida / Marian Provazi Orioli / Bruno Chaboli Gambarato Luciano Rodrigues Costa / Claudia Yamada Utagawa

Tabela 1. Número (porcentagem) de participantes distribuídos de acordo com o resultado do teste de triagem neonatal

\begin{tabular}{llll}
\hline Doenças & Normal & Alterados & Não consta \\
\hline Hipotireoidismo congênito & $47(23 \%)$ & $2(1 \%)$ & $155(76 \%)$ \\
\hline Fenilcetonúria & $49(24 \%)$ & $0(0 \%)$ & $155(76 \%)$ \\
\hline $\begin{array}{l}\text { Anemia Falciforme e outras } \\
\text { Hemoglobinopatias }\end{array}$ & $48(23,5 \%)$ & $1(0,5 \%)$ & $155(76 \%)$ \\
\hline Deficiência de Biotinidase & $44(21,5 \%)$ & $0(0 \%)$ & $160(78,5 \%)$ \\
\hline Fibrose cística & $42(20,5 \%)$ & $2(1 \%)$ & $160(78,5 \%)$ \\
\hline Hiperplasia adrenal congênita & $42(20,5 \%)$ & $0(0 \%)$ & $162(79,5 \%)$ \\
\hline Outros & $9(4,5 \%)$ & $0(0 \%)$ & $195(95,5 \%)$ \\
\hline
\end{tabular}

Fonte: Confeccionada pelos autores

Dentre os sujeitos de pesquisa, um obteve resultado alterado tanto para hipotireoidismo congênito quanto para fibrose cística. Essa criança é do sexo feminino e tinha dois meses de idade no momento da aplicação do formulário. O segundo paciente com alteração para hipotireoidismo congênito é do sexo masculino e tinha seis anos. 0 que possuía alteração para fibrose cística é do sexo masculino e tinha oito anos de idade. A criança que recebeu o resultado alterado para anemia falciforme e outras hemoglobinopatias tinha dois anos no dia da coleta de dados e é do sexo masculino. Dessa forma, foi encontrado cinco testes alterados, sendo quatro participantes afetados.

\section{DISCUSSÃO}

O teste de triagem bioquímica é feito nos pontos disponíveis na Atenção Básica em Saúde, como também nas maternidades, casas de parto e comunidades indígenas. Independentemente do local em que seja realizado, a coleta deve ser documentada e registrada no sistema de informação SISNEO Centralizador, quando disponível (MINISTÉRIO DA SAÚDE, 2016, 2020). O período ideal de coleta da primeira amostra é entre o terceiro e o quinto dia de vida da criança (MINISTÉRIO DA SAÚDE, 2016). E, segundo a Sociedade Brasileira de Endocrinologia e Metabologia (2017), o resultado deve ser entregue até 15 dias de vida.

Os dados apresentados revelam que, das 18 crianças que aguardavam o resultado, $83 \%(n=15)$ tinham entre dezessete dias e três anos de idade, ou seja, ultrapassaram o prazo indicado. Essa informação é digna de análise e preocupação, pois as doenças triadas precisam de diagnóstico e tratamento precoces. A exemplificação desse fato é que, após a alteração no resultado no teste de triagem neonatal, os testes laboratoriais para confirmação do hipotireoidismo congênito devem ser realizados entre a primeira e segunda semanas de vida do recém-nascido (SOCIEDADE BRASILEIRA DE PEDIATRIA, 2018). Ademais, a triagem da fibrose cística é feita por meio de duas dosagens dos níveis de tripsinogênio imunorreativo, sendo que a segunda deve ser realizada até 30 dias de vida. Além disso, caso haja alteração na triagem neonatal, a criança deve fazer o teste do suor com idade entre 4 e 6 semanas (ATHANAZIO et al., 2017).

Atualmente, o programa brasileiro de triagem neonatal tem em seu escopo seis doenças: fenilcetonúria, hipotireoidismo congênito, doença falciforme e outras hemoglobinopatias, fibrose cística, hiperplasia adrenal congênita e deficiência de biotinidase (MINISTÉRIO DA SAÚDE, 2016). Os principais aspectos de cada uma podem ser encontrados no quadro a seguir: 
Quadro 2. Principais aspectos das doenças triadas pelo PNTN

\begin{tabular}{|c|c|c|c|c|}
\hline DOENÇA & CAUSA & ETIOLOGIA & CLÍNICA & TRATAMENTO \\
\hline Fenilcetonúria & $\begin{array}{l}\text { Ausência ou defi- } \\
\text { ciência de atividade } \\
\text { da enzima fenilalani- } \\
\text { na hidroxilase. }\end{array}$ & $\begin{array}{l}\text { Padrão genético autos- } \\
\text { sômico recessivo. }\end{array}$ & $\begin{array}{l}\text { Atraso do desenvolvi- } \\
\text { mento neuropsicomo- } \\
\text { tor, deficiência mental, } \\
\text { padrão autista, convul- } \\
\text { sões e odor caracterís- } \\
\text { tico na urina. }\end{array}$ & $\begin{array}{l}\text { Restrição dietética de } \\
\text { fenilalanina e monito- } \\
\text { rização dos níveis de } \\
\text { fenilalanina séricos. }\end{array}$ \\
\hline $\begin{array}{l}\text { Hipotireoidismo } \\
\text { Congênito }\end{array}$ & $\begin{array}{l}\text { Deficiência do hor- } \\
\text { mônio tireoidiano. }\end{array}$ & $\begin{array}{l}\text { Disgenesia tireoidiana } \\
\text { (mutações genéticas em } \\
\text { fatores de transição), } \\
\text { disormonogênese (ge- } \\
\text { ralmente autossômica } \\
\text { recessiva). Quando } \\
\text { transitório, decorre do } \\
\text { uso materno de medica- } \\
\text { mentos antitireoidianos, } \\
\text { exposição materna ou } \\
\text { neonatal a agentes ioda- } \\
\text { dos, passagem transpla- } \\
\text { centária de anticorpos } \\
\text { maternos que bloqueiam } \\
\text { o receptor de TSH, defi- } \\
\text { ciência da ingestão de } \\
\text { iodo, mutações em he- } \\
\text { terozigose nas enzimas } \\
\text { DUOX1 ou DUOX2/ THOX } \\
\text { e grandes hemangiomas } \\
\text { hepáticos. }\end{array}$ & $\begin{array}{l}\text { Destaca-se hipotonia } \\
\text { muscular, dificuldades } \\
\text { respiratórias, icterícia, } \\
\text { anemia, livedo reticula- } \\
\text { ris, choro rouco, hérnia } \\
\text { umbilical, alargamento } \\
\text { de fontanela, sopro } \\
\text { cardíaco, dificuldade } \\
\text { na alimentação com } \\
\text { deficiente crescimento } \\
\text { ponderal, retardo na } \\
\text { maturação óssea. }\end{array}$ & $\begin{array}{l}\text { Reposição oral de } \\
\text { levotiroxina, com mo- } \\
\text { nitorização clínica do } \\
\text { desenvolvimento e do } \\
\text { crescimento, e dosa- } \\
\text { gem dos níveis séricos } \\
\text { de TSH e T4 livre. }\end{array}$ \\
\hline $\begin{array}{l}\text { Doenças Falci- } \\
\text { formes e outras } \\
\text { Hemoglobino- } \\
\text { patias }\end{array}$ & $\begin{array}{l}\text { Produção anormal de } \\
\text { cadeias } \beta \text { da hemo- } \\
\text { globina. }\end{array}$ & $\begin{array}{l}\text { Padrão genético autos- } \\
\text { sômico recessivo. }\end{array}$ & $\begin{array}{l}\text { Febre alta, anemia } \\
\text { hemolítica crônica e } \\
\text { crises intermitentes } \\
\text { vaso-oclusivas, crises } \\
\text { de dor, insuficiência } \\
\text { renal progressiva, } \\
\text { maior susceptibilidade } \\
\text { a infecções e seques- } \\
\text { tro esplênico, além de } \\
\text { possíveis alterações } \\
\text { no desenvolvimento } \\
\text { neurológico. }\end{array}$ & $\begin{array}{l}\text { Não possui tratamen- } \\
\text { to, mas o diagnóstico } \\
\text { precoce permite orien- } \\
\text { tação em relação a } \\
\text { cuidados preventivos } \\
\text { com profilaxia de infec- } \\
\text { ções e imunizações. }\end{array}$ \\
\hline Fibrose Cística & $\begin{array}{l}\text { Distúrbio de função } \\
\text { da proteína regula- } \\
\text { dora da condutância } \\
\text { transmembrana } \\
\text { (CFTR) que leva } \\
\text { ocorre aumento da } \\
\text { viscosidade do muco } \\
\text { que desencadeia um } \\
\text { processo obstrutivo. }\end{array}$ & $\begin{array}{l}\text { Padrão genético autos- } \\
\text { sômico recessivo. }\end{array}$ & $\begin{array}{l}\text { Bloqueio das vias } \\
\text { aéreas propicia a pro- } \\
\text { liferação bacteriana, } \\
\text { disfunção respiratória, } \\
\text { má nutrição. }\end{array}$ & $\begin{array}{l}\text { Suporte nutricional, } \\
\text { com suplementação de } \\
\text { vitaminas A, D, E e K e } \\
\text { reposição de enzimas } \\
\text { produzidas pelo pân- } \\
\text { creas, fisioterapia res- } \\
\text { piratória e prevenção } \\
\text { de infecções. }\end{array}$ \\
\hline $\begin{array}{l}\text { Hiperplasia } \\
\text { Adrenal Congê- } \\
\text { nita }\end{array}$ & $\begin{array}{l}\text { Deficiências enzi- } \\
\text { máticas na biossín- } \\
\text { tese dos esteroides } \\
\text { adrenais, cortisol e } \\
\text { aldosterona. }\end{array}$ & $\begin{array}{l}\text { Padrão genético autos- } \\
\text { sômico recessivo. }\end{array}$ & $\begin{array}{l}\text { Depende da enzima } \\
\text { envolvida, podendo se } \\
\text { expressar por insufi- } \\
\text { ciência glicocorticoide, } \\
\text { insuficiência mineralo- } \\
\text { corticoide, excesso ou } \\
\text { insuficiência de andró- } \\
\text { genos. }\end{array}$ & $\begin{array}{l}\text { Reposição hormonal de } \\
\text { acordo com a manifes- } \\
\text { tação. }\end{array}$ \\
\hline $\begin{array}{l}\text { Deficiência de } \\
\text { Biotinidase }\end{array}$ & $\begin{array}{l}\text { Desarranjo no me- } \\
\text { tabolismo da biotina } \\
\text { com sua consequen- } \\
\text { te depleção. }\end{array}$ & $\begin{array}{l}\text { Padrão genético autos- } \\
\text { sômico recessivo. }\end{array}$ & $\begin{array}{l}\text { Distúrbios neurológi- } \\
\text { cos e cutâneos, como } \\
\text { crises epiléticas, hi- } \\
\text { potonia, microcefalia, } \\
\text { atraso do desenvol- } \\
\text { vimento neuropsico- } \\
\text { motor, perda auditiva, } \\
\text { distúrbios visuais, } \\
\text { alopécia e dermatite } \\
\text { eczematoide. }\end{array}$ & $\begin{array}{l}\text { Reposição oral da bio- } \\
\text { tina. }\end{array}$ \\
\hline
\end{tabular}

Fonte: Confeccionado pelos autores com base em (SOUZA; SCHWARTZ; GIUGLIANI, 2002; WEBER; SCHOLL; BAUMGARTNER, 2004; MINISTÉRIO DA SAÚDE; DEPARTAMENTO DE ATENÇÃO ESPECIALIZADA, 2005; SANTOS et al., 2005; CAMPBELL; WHITE, 2005; SANTOS et al., 2005; GROSSE et al., 2006; ROCK, 2007; SIMS et al., 2007; LEÃO; AGUIAR, 2008; MINISTÉRIO DA SAÚDE, 2016; SOCIEDADE BRASILEIRA DE PEDIATRIA, 2018). 
Marcela Leone Pereira de Oliveira / Anderson de Souza Mendonça Junior / Isabelly Nascimento Souza / Julio Cesar Goulart Fonseca / Amanda Freire de Almeida / Marian Provazi Orioli / Bruno Chaboli Gambarato Luciano Rodrigues Costa / Claudia Yamada Utagawa

Dentre as 204 crianças que já haviam recebido o resultado do teste de triagem neonatal, $2 \%(n=4)$ possuíam alterações. Esse dado reforça a importância da triagem neonatal bioquímica como ação preventiva que permite realizar o diagnóstico de diversas doenças de forma precoce, possibilitando, assim, um tratamento precoce e a eliminação ou diminuição de sequelas causadas por essas doenças (SBTEIM, 2020).

A incidência de hipotireoidismo congênito é de $0,04 \%$ a 0,02\% dos nascidos vivos no Brasil (CARVALHO et al., 2007; MACIEL et al., 2013). No presente estudo, foram encontrados dois casos (1\%) dessa doença, dentre 204 participantes que receberam o resultado do teste. No estado do Rio de Janeiro, a incidência de anemia falciforme é de 0,08\% dos nascidos vivos (KATO et al., 2018). Em nosso estudo, houve um $(0,5 \%)$ teste alterado para anemia falciforme. Quanto à fibrose cística, sua incidência no Brasil é $0,01 \%$ dos nascidos vivos (ATHANAZIO et al., 2017) e, em nossa pesquisa, foram encontrados dois casos (1\%).

O PNTN é dividido em cinco etapas. A primeira compreende a realização do teste propriamente dito. A segunda etapa é composta pelo acompanhamento do resultado e pela busca ativa, seguida pela localização dos recém-nascidos e suas famílias para entrega dos resultados, principalmente se o resultado estiver alterado. A terceira etapa é a realização dos testes específicos, que variam de acordo com a doença e que, frequentemente, requerem laboratórios especializados, a fim de se afastar os resultados falso-positivos. A quarta etapa diz respeito ao tratamento, que, muitas vezes, é por toda a vida e deve ser acompanhado por uma equipe interprofissional. A quinta etapa é a avaliação periódica das etapas anteriores, verificando-se o benefício para a sociedade. O American College of Medical Genetics recomenda uma sexta etapa, que consiste na educação em saúde dos profissionais e comunidade (LEÃO; AGUIAR, 2008).

$\mathrm{Na}$ segunda etapa, com a entrega dos resultados, esses devem ser anotados na caderneta de saúde da criança. Essa etapa é relevante já que, de acordo com um estudo realizado na França, o preenchimento correto da caderneta revela a importância que os profissionais atribuem ao indicador em questão e auxilia no processo de educação em saúde e conscientização dos pais (VINCELET et al., 2003).

Ao analisar os dados encontrados no presente artigo, é possível identificar que $73 \%(n=162)$ dos sujeitos de pesquisa não tiveram o resultado do teste de triagem bioquímica anotado na caderneta da saúde da criança. 0 artigo de Abud e Gaíva (2016) revela que 85,9\% ( $n=816)$ das 950 cadernetas analisadas não tiveram o campo do "teste do pezinho" preenchidos, sendo um dos índices mais baixos de preenchimento, quando comparado com os outros campos. Ademais, Abud et al. (2015) e Amorim et al. (2018) indicam que o preenchimento da caderneta foi insatisfatório.

Segundo Lima et al. (2016), dentre os principais fatores que influenciam no uso inadequado da CSC estão a carência e a fragilidade de registros, a dificuldade dos profissionais de saúde de perceberam a relevância do preenchimento e o conhecimento deficiente por parte desses profissionais.

Ao utilizar adequadamente a caderneta, o profissional de saúde faz com que a família valorize as informações contidas no instrumento. Além de disso, corresponsabiliza os cuidadores pelas ações em saúde da criança, proporcionando um cuidado integral (SILVA et al., 2015). Ademais, o correto preenchimento da CSC fornece dados para a vigilância epidemiológica e permite a formulação de políticas de saúde. 


\section{CONCLUSÃO}

Embora o presente artigo seja uma análise preliminar, é incontestável que há uma falha na segunda etapa do PNTN. Quando levado em consideração o prazo para entrega do resultado, observou-se que uma parcela expressiva ( $7 \%$ dos sujeitos de pesquisa não o recebeu no tempo adequado. Tal dado revela uma ineficiência do programa, pois não está cumprindo o objetivo de rastreio, o que impede um diagnóstico precoce. Assim, cria-se um risco para a saúde das crianças do Médio Paraíba.

Além disso, percebeu-se que o preenchimento da caderneta de saúde da criança foi inadequado, considerando que $73 \%$ não tiveram o resultado do teste anotado. Assim, é imprescindível ressaltar a necessidade de capacitação e atualização dos profissionais de saúde por meio da educação continuada.

Por se tratar de resultados parciais, é necessária uma amostra maior para que a incidência das patologias pesquisadas pelo PNTN na região do Médio Paraíba seja calculada de forma fidedigna.

\section{REFERÊNCIAS}

ABUD, S. M. et al. Records of growth and development data in the child health handbook. Revista Gaúcha de Enfermagem, v. 36, n. 2, p. 97-105, jun. 2015.

ABUD, S. M.; GAÍVA, M. A. M. Análise do preenchimento dos dados sobre gravidez, parto, puerpério e recém-nascido na caderneta de saúde da criança. Rev. Soc. Bras. Enferm. Ped. v. 16, n. 1, p. 10, jun. 2016.

AMORIM, L. DE P. et al. Avaliação do preenchimento da Caderneta de Saúde da Criança e qualidade do preenchimento segundo o tipo de serviço de saúde usado pela criança. Ciência \&amp; Saúde Coletiva, v. 23, n. 2, p. 585-597, fev. 2018.

ATHANAZIO, R. A. et al. Diretrizes brasileiras de diagnóstico e tratamento da fibrose cística. Jornal Brasileiro de Pneumologia, v. 43, n. 3, p. 219-245, jun. 2017.

BRASIL. Ministério da Saúde. Gabinete do Ministro. Portaria n ${ }^{\circ} .829$, de 14 de dezembro de 2012. Inclui a Fase IV no Programa Nacional de Triagem Neonatal (PNTN), instituído pela Portaria n 822/GM/MS, de 6 de junho de 2001. Diário Oficial da União, Brasília, DF, 14 dez. 2012. Seção 1, p. 54.

CAMPBELL, P. W.; WHITE, T. B. Newborn screening for cystic fibrosis: an opportunity to improve care and outcomes. The Journal of Pediatrics, v. 147, n. 3 Suppl, p. S2-5, set. 2005.

CARVALHO, T. M. DE et al. Newborn screening: A national public health programme in Brazil. Journal of Inherited Metabolic Disease, v. 30, n. 4, p. 615-615, 2007.

GROSSE, S. D. et al. Potential impact of newborn screening for cystic fibrosis on child survival: a systematic review and analysis. The Journal of Pediatrics, v. 149, n. 3, p. 362-366, set. 2006.

KATO, G. J. et al. Sickle cell disease. Nature Reviews Disease Primers, v. 4, n. 1, p. 1-22, 15 mar. 2018.

KHOURY, M. J.; MCCABE, L. L.; MCCABE, E. R. B. Population screening in the age of genomic medicine.

The New England Journal of Medicine, v. 348, n. 1, p. 50-58, 2 jan. 2003. 
Marcela Leone Pereira de Oliveira / Anderson de Souza Mendonça Junior / Isabelly Nascimento Souza / Julio Cesar Goulart Fonseca / Amanda Freire de Almeida / Marian Provazi Orioli / Bruno Chaboli Gambarato Luciano Rodrigues Costa / Claudia Yamada Utagawa

LEÃO, L. L.; AGUIAR, M. J. B. DE. Triagem neonatal: o que os pediatras deveriam saber. Jornal de Pediatria, v. 84, n. 4 , p. S80-S90, ago. 2008.

LIMA, L. et al. A Utilização da Caderneta de Saúde da Criança no acompanhamento Infantil. Revista Brasileira de Ciências da Saúde, v. 20, n. 2, p. 167-174, 2016.

LINDEGREN, M. L. et al. Applying public health strategies to primary immunodeficiency diseases: a potential approach to genetic disorders. MMWR. Recommendations and reports: Morbidity and mortality weekly report. Recommendations and reports, v. 53, n. RR-1, p. 1-29, 16 jan. 2004.

LUMERTZ, M. S. et al. False-negative newborn screening result for immunoreactive trypsinogen: a major problem in children with chronic lung disease. Jornal Brasileiro de Pneumologia, v. 45, n. 3, 2019.

MACIEL, L. M. Z. et al. Congenital hypothyroidism: recommendations of the Thyroid Department of the Brazilian Society of Endocrinology and Metabolism. Arquivos Brasileiros De Endocrinologia E Metabologia, v. 57, n. 3, p. 184-192, abr. 2013.

MINISTÉRIO DA SAÚDE. Triagem Neonatal Biológica: Manual Técnico. 1a edição ed. Brasília, DF: [s.n.]. v. 1

MINISTÉRIO DA SAÚDE. Dados sobre o Programa Nacional de Triagem Neonatal. Disponível em: https:// www.saude.gov.br/acoes-e-programas/programa-nacional-da-triagem-neonatal/dados-sobre-oprograma-nacional-de-triagem-neonatal. Acesso em: 15 maio. 2020.

MINISTÉRIO DA SAÚDE. Indicadores da Triagem Neonatal no Brasil. Disponível em: https://www.saude. gov.br/acoes-e-programas/programa-nacional-da-triagem-neonatal/indicadores-da-triagem-neonatalno-brasil. Acesso em: 15 maio 2020.

MINISTÉRIO DA SAÚDE. Programa Nacional da Triagem Neonatal. Disponível em: https://www.saude. gov.br/acoes-e-programas/programa-nacional-da-triagem-neonatal. Acesso em: 7 ago. 2020.

MINISTÉRIO DA SAÚDE; DEPARTAMENTO DE ATENÇÃO ESPECIALIZADA. Manual de normas técnicas e rotinas operacionais do Programa Nacional de Triagem Neonatal. Brasília, DF: Editora MS, 2005.

RAMALHO, A. S.; MAGNA, L. A.; PAIVA-E-SILVA, R. B. DE. A Portaria no 822/01 do Ministério da Saúde e as peculiaridades das hemoglobinopatias em saúde pública no Brasil. Cadernos de Saúde Pública, v. 19, n. 4, p. 1195-1199, ago. 2003.

ROCK, M. J. Newborn screening for cystic fibrosis. Clinics in Chest Medicine, v. 28, n. 2, p. 297-305, jun. 2007.

SANTOS, G. P. C. et al. Programa de triagem neonatal para fibrose cística no estado do Paraná: avaliação após 30 meses de sua implantação. Jornal de Pediatria, v. 81, n. 3, jun. 2005.

SBTEIM. 0 que é triagem neonatal. Disponível em: https://www.sbteim.org.br/. Acesso em: 27 jul. 2020.

SILVA, F. B. E et al. Use of the child health record by families: perceptions of professionals. Texto \& Contexto - Enfermagem, v. 24, n. 2, p. 407-414, jun. 2015.

SIMS, E. J. et al. Economic implications of newborn screening for cystic fibrosis: a cost of illness retrospective cohort study. Lancet (London, England), v. 369, n. 9568, p. 1187-1195, 7 abr. 2007. 
SOCIEDADE BRASILEIRA DE ENDOCRINOLOGIA E METABOLOGIA. 10 Coisas sobre o Teste do Pezinho. Disponível em: https://www.endocrino.org.br/10-coisas-sobre-o-teste-do-pezinho/. Acesso em: 1 ago. 2020.

SOCIEDADE BRASILEIRA DE PEDIATRIA. Hipotireoidismo Congênito: Triagem Neonatal, nov. 2018. Disponível em: https://www.sbp.com.br/fileadmin/user_upload/_21369c-DC_Hipotireoidismo_Congenito. pdf. Acesso em: 27 jul. 2020

SOUZA, C. F. M. DE; SCHWARTZ, I. V.; GIUGLIANI, R. Triagem neonatal de distúrbios metabólicos. Ciência \& Saúde Coletiva, v. 7, p. 129-137, 2002.

VINCELET, C. et al. Le carnet de santé de l'enfant est-il informatif ? Évaluation dans différentes structures de prévention et de soins. Archives de Pédiatrie, v. 10, n. 5, p. 403-409, 1 maio 2003. 